\title{
Influence of Deep Cryogenic Treatment (DCT) on Thermo Mechanical Performance of AISI H13 Tool Steel
}

\author{
Valmik Bhawar, Shreyans Khot, Prakash Kattire, Mohan Mehta, Rajkumar Singh \\ Kalyani Center for Technology and Innovation, Bharat Forge Ltd., Pune, India \\ Email: Prakash.kattire@bharatforge.com
}

How to cite this paper: Bhawar, V., Khot, S., Kattire, P., Mehta, M. and Singh, R. (2017) Influence of Deep Cryogenic Treatment (DCT) on Thermo Mechanical Performance of AISI H13 Tool Steel. Journal of Materials Science and Chemical Engineering, 5, 91-101.

http://dx.doi.org/10.4236/msce.2017.51013

Received: December 15, 2016

Accepted: January 13, 2017

Published: January 16, 2017

\begin{abstract}
Deep cryogenic treatment (DCT) is one of the most recent processes being used to treat tool steels. It is a supplementary treatment where components are treated below subzero temperatures for several cryo-soaking hours. This paper focuses on to study the effect of deep cryogenic treatment on Thermo mechanical properties of AISI H-13 tool steel. Deep cryogenic treatment at 32 hours of cryo-soaking time is applied and thermo mechanical performance of tool steel was analyzed by using pin on disk high temperature wear testing and stress rupture testings. The microstructural evolutions during DCT were evaluated by using scanning electron microscope (SEM). It was observed that microstructural modifications like increase in carbide density, fine and uniform martensitic structure during DCT had significantly improved properties.
\end{abstract}

\section{Keywords}

Cryogenic Treatment, Wear Resistance, Tool Steel, H-13 Tool Steel

\section{Introduction}

AISI H13 Hot work tool steel is used in making various tools. However in working condition these tools undergo surface failures like wear, deformation, cracks. Although conventional heat treatments are available like hardening and tempering, nitriding but treatments like DCT will further improve performance of tool material. In Deep cryogenic treatment material to be treated is kept at $-190^{\circ} \mathrm{C}$ for long hours and slowly brought to room temperature followed by tempering. Several treatment time and temperature profiles are available depending on the material and volume to be treated. DCT can be used for wide range of industrial tooling applications, like machining tools (milling, cutting, 
drilling etc.) and press tools (hot and cold forging dies, extrusion dies, punches, shearing tools etc.) because it enhances tool life which results in cost savings. It is a one-time and permanent treatment where entire mass is treated so that benefits could be realized even after regrinding or re-sharpening of tools unlike in surface treatments. Though DCT has several benefits, it is an additional treatment along with conventional heat treatment and not a replacement of it [1]. It is usually carried out after conventional heat treatment, like hardening and tempering. Several advantages of cryogenic treatment like increase in hardness and tensile strength, increase in wear resistance, more impact toughness, low brittleness, low residual stresses and higher thermal stability, are particularly useful for tool steels to enhance fatigue life [2] [3]. While improvements of $44 \%$ $126 \%$ [4] and 301\% [5] in tool life were recorded, the reported improvement in wear rate was in the range of $56 \%-87 \%$ [6] in case of M2 HSS tool steels. Similarly, significant improvements in tool life and wear rate were also reported for M35 HSS tool steels [7] [8]. In the similar lines, published literature on D3 and D6 type tool steel demonstrated 39\% - 68\% [9] and 52\% [10] improvements in wear rate. However, the microstructural mechanisms which are responsible for these improvements are not yet fully understood and needs further investigations [11] [12]. Some of the common mechanisms which are discussed in most of the literatures are complete transformation of retained austenite to martensite, precipitation of tertiary carbides (ETA carbides) and their uniform distribution in martensitic matrix and creation of more denser molecular structure [4] [5] [13].

Zbigniew Latas et al. [14] did research on cryogenic processing of hot forging tool steels (55NiCrMoV6 and X38CrMoV5-1) and claimed significant increase in the hardness and wear resistance by using DCT as compared to the conventional heat treatment. M. Parez et al. [15] claimed 22\% - 24\% improvement in fracture toughness of cryogenically treated $\mathrm{H}-13$ tool steel as compared to conventional treatment. Mahdi Koneshlou et al. [13] examined the effect of DCT on AISI H-13 tool steel where they reported improvement in hardness, tensile strength, impact energy and wear resistance. The improvement in these properties was explained by the transformation of retained austenite to martensite, precipitation of very fine carbides and more uniform \& smaller martensitic lath microstructure. Adam Cicek et al. [16] compared effect of cryogenic and hardening heat treatment on machinability of h13 tool steel and found reduction in wear rate, surface roughness and cutting forces for cryogenically treated steel.

Though wide literature is available on DCT stating its advantages in terms of wear resistance and mechanical properties, less emphasis is given on thermo mechanical properties of tool steels. This is the main focus of the presented investigations on the AISI H-13 tool steel.

\section{Materials and Experimental Procedure}

\subsection{Experimental}

The commercial grade of AISI H-13 tool steel was selected for the present work. Table 1 shows chemical composition of this material in annealed condition 
Table 1. Chemical composition of AISI H-13 tool steel (annealed condition).

\begin{tabular}{ccccccccccc}
\hline Elements & $\mathrm{C}$ & $\mathrm{Mn}$ & $\mathrm{Si}$ & $\mathrm{Cr}$ & $\mathrm{Ni}$ & $\mathrm{Mo}$ & $\mathrm{V}$ & $\mathrm{S}$ & $\mathrm{P}$ & $\mathrm{Fe}$ \\
\hline Weight \% & 0.385 & 0.35 & 1.049 & 5.11 & 0.152 & 1.278 & 0.993 & 0.001 & 0.014 & Remaining \\
\hline
\end{tabular}

which was analyzed by vacuum emission spectrometer. Small samples of appropriate dimensions required for microstructural, hardness, stress rupture and wear analysis were prepared from this material for planned research. All prepared samples were then exposed to regular heat treatment including hardening and tempering. Both of these treatments were carried out in muffle furnace with controlled heating. During hardening samples were held at $1030^{\circ} \mathrm{C}$ for $60 \mathrm{mi}-$ nutes for austenitizing followed by quenching in oil stirred bath. After hardening, samples were then tempered at $560^{\circ} \mathrm{C}$ for 2 hours followed by air cooling to room temperature. This was the conventional heat treatment cycle used for all specimens under consideration in this study and samples named as harden \& tempered (HT) samples.

Few samples from HT group were then deep cryogenically treated in a computer controlled cryo-processor (Sanmer make, $-185^{\circ} \mathrm{C}$ ). The temperature inside the cryo-processor was controlled by supplying calculated gasified liquid nitrogen through solenoid valve. The samples were first cooled down to $-185^{\circ} \mathrm{C}$ at the rate of $3^{\circ} \mathrm{C} / \mathrm{min}$ to avoid thermal shock and then soaked for 32 hour as shown in Figure 1. After the completion of soaking time, samples were removed from the cryo-processor and stored in insulated thermocol until they attain room temperature. All samples were then processed through soft tempering at $110^{\circ} \mathrm{C}$ with 2 hours soaking, followed by air cooling to room temperature.

\subsection{Characterization}

Microstructural analysis was carried out by using scanning electron microscope (EV018 Carl Zeiss make). The samples were subjected to series of emery paper $(1 / 0,2 / 0,3 / 0$ and $4 / 0)$ polishing followed by velvet cloth polishing with intermittent application of fine suspension of diamond paste. Finally samples were cleaned with acetone and etched with $2 \%$ nital etchant. The impact toughness of already prepared notched samples (as per ASTM A370 standard) was determined by using Zwick Roell make impact tester. Average impact toughness (J) of three samples for each material condition was taken as measure of impact toughness. Hardness measurement was carried out on Matsuawa with Celmex make micro-hardness tester.

Samples were polished by using 300 and $400 \mathrm{G}$ polish papers before hardness testing. The averages of three measurements were recorded for each material condition.

Stress rupture tests were conducted with Applied Test System (ATS) model 2410 having three zone furnace controlled by WINCCS software. The specimens used for stress rupture testing were similar to that used for tensile test (ASTM standard E8-91). Test setup and specimen conditions are shown in Figure 2. The specimen was placed in the center zone of the furnace to maintain a constant 


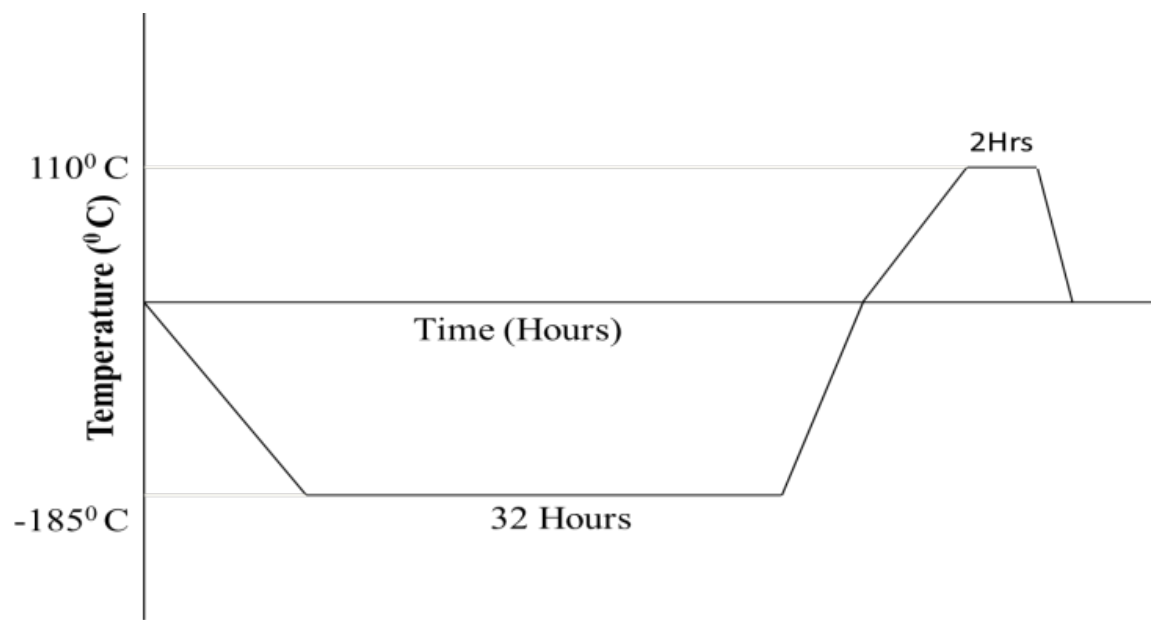

Figure 1. Deep cryogenic treatment (DCT) cycle.
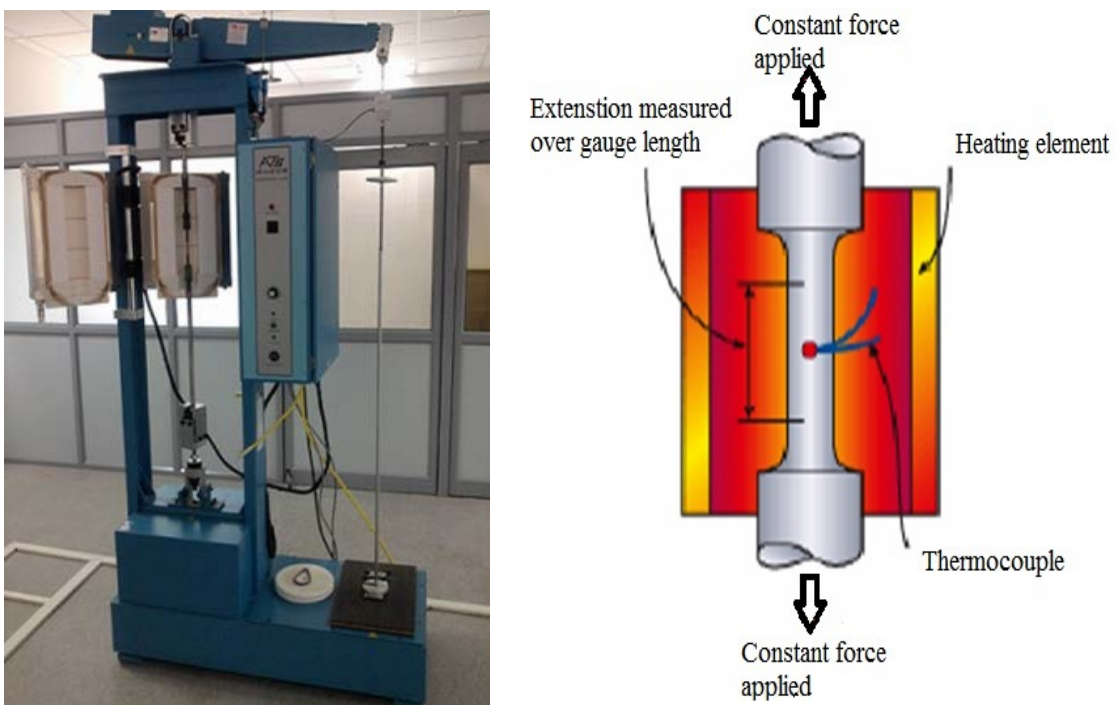

Figure 2. ATS creep testing setup \& stress rupture specimen test condition.

temperature along the gauge length of the specimen. Thermocouples were attached to top and bottom of specimen to monitor the specimen temperature during the test. The specimens were gripped in the furnace with the help of assembly.

The creep tests were conducted by using following procedure based on the standard practice ASTM E139-83. Load required to apply in pan is calculated as [17]

$$
w=\frac{(s * a)}{r}
$$

where, $w$-amount of load to be placed in pan, $s$-stress required, $a$-Cross section of specimen and $r$-Lever arm ratio.

The test was started with a preload of about $5 \%-10 \%$ of the total load. Next, the test piece was heated. When the required temperature was reached, the sample was soaked for about $60 \mathrm{~min}$. The load was applied without any jerk. The test load was applied along the test axis in such a manner that it minimized the 
bending and torsion of the test specimen. The WINCCS software provides computer automation of the entire creep test process. After completion of the test, the specimen dimensions were measured for calculation of percentage elongation and reduction of area. In stress rupture test, range of stresses applied was 120 to $600 \mathrm{MPa}$. Temperature was varied from $550^{\circ} \mathrm{C}$ to $650^{\circ} \mathrm{C}$. For the present research work based on forging die working condition applied stress was $600 \mathrm{MPa}$ and temperature was $650^{\circ} \mathrm{C}$.

High temperature wear testing was carried out on pin-on-disk DUCOM make tribometer. The samples shown in Figure 3 were manufactured and given planned treatments as already described. Pins with two different types of material conditions (HT \& DCT32) were tested. This tribometer works on the Archimedes equation given below.

$$
k=\Delta V / F L
$$

where, $k$-wear rate in $\mathrm{mm}^{3} / \mathrm{Nm}, \Delta V$-the worn out volume of material $\left(\mathrm{mm}^{3}\right)$, $F$-normal force and $L$-sliding distance.

Disk and sample pins were cleaned with acetone to avoid any surface contamination. Fresh disk track was used for every new experiment. Table 2 shows testing parameters which were used during wear testing. The results of wear testing reported in terms of weight loss of pins and wear rate. Weight loss of pins was calculated by taking weight of pin before and after testing whereas wear rate was calculated by using Archimedes equation as mentioned above.

\section{Result and Discussion}

\subsection{Microstructural Analysis}

The microstructure of harden and tempered (HT) sample shows needle type

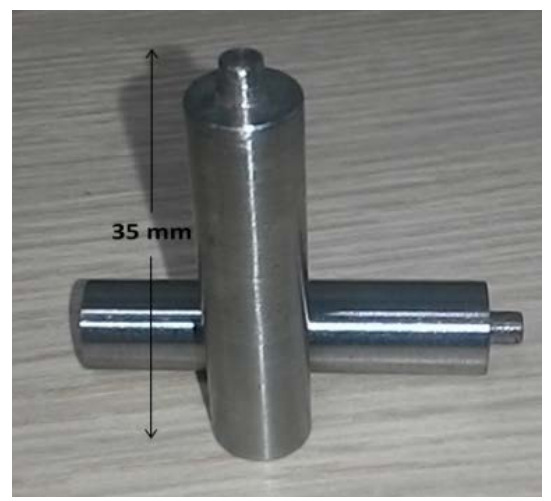

Figure 3. Wear test pin samples.

Table 2. Testing parameters used for wear testing.

\begin{tabular}{ccccc}
\hline & \multicolumn{4}{c}{ Parameters } \\
\cline { 2 - 5 } & Testing pin temperature & Load & $\begin{array}{c}\text { Sliding } \\
\text { velocity }\end{array}$ & $\begin{array}{c}\text { Sliding } \\
\text { distance }\end{array}$ \\
\hline Value & 400 & 150 & 1.0 & 1800 \\
\hline
\end{tabular}


tempered martensitic structure (Figure 4(a)) along with carbides of chromium, molybdenum and vanadium. The evolution of microstructure by execution of deep cryogenic treatment is shown in Figure 4(b). It is observed that martensitic needles are finer in case of cryogenically treated samples.

The microstructure of conventional (HT) sample shows mainly primary and secondary carbides as shown in Figure 5(a). In case of cryogenically treated

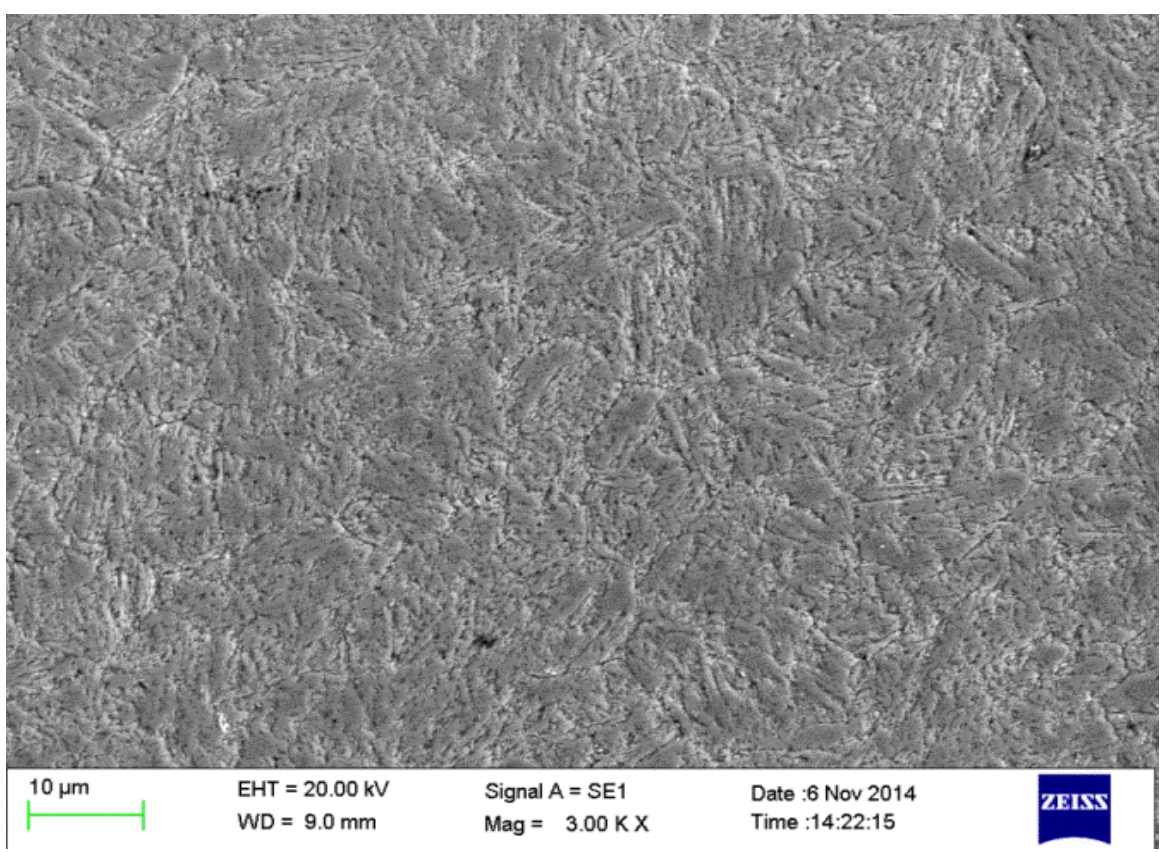

(a)

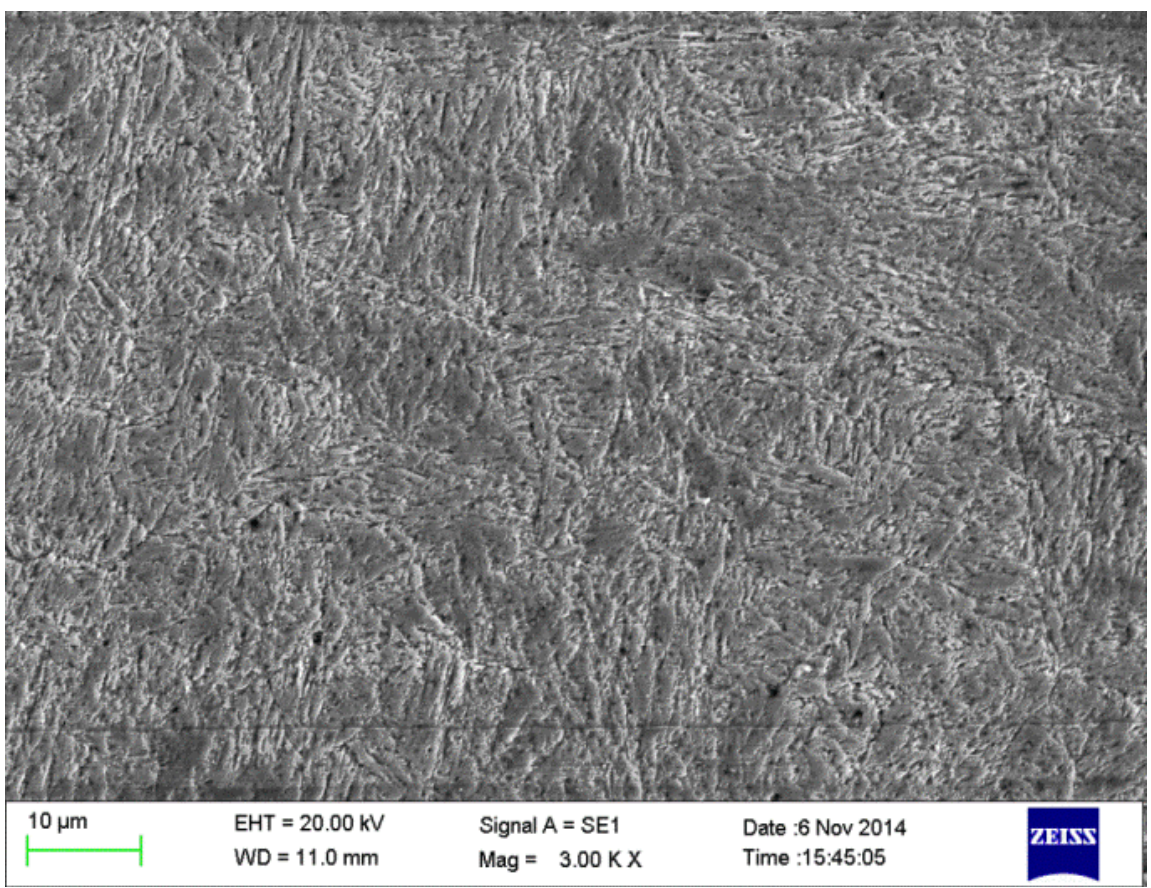

(b)

Figure 4. SEM images showing tempered martensitic structure (a) inconventional (HT) and cryogenically treated (DCT) sample (b). 


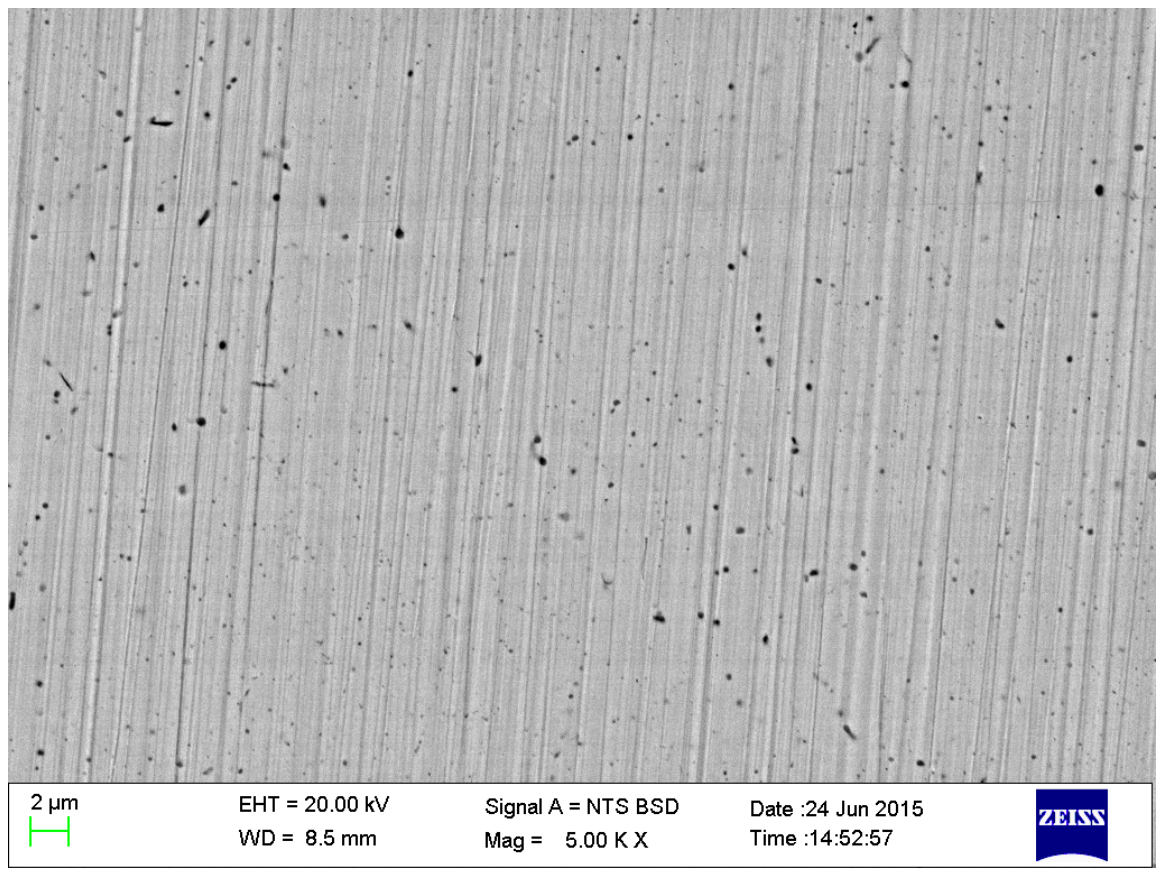

(a)

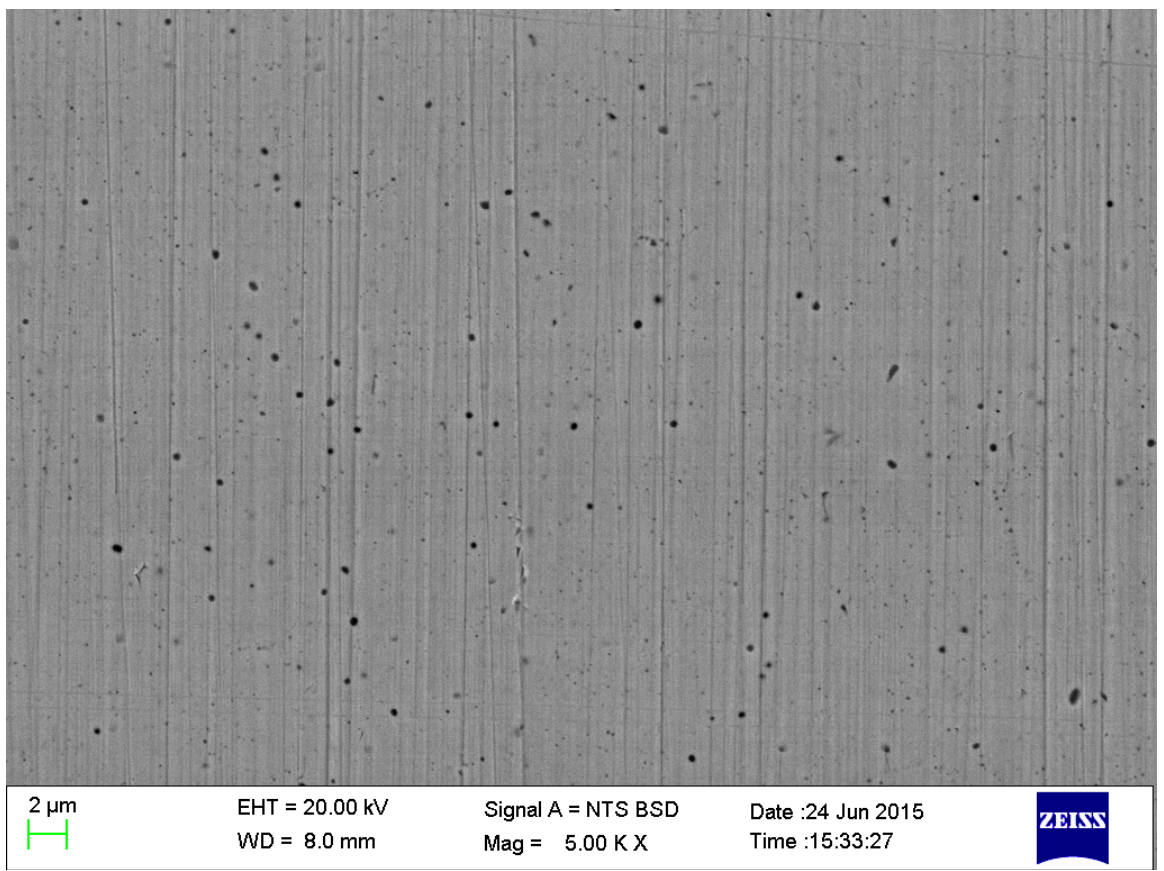

(b)

Figure 5. SEM images showing carbides in conventional (a) and cryogenically treated (b) samples.

sample (Figure 5(b)), very fine carbides (tertiary carbides) are also present along with primary and secondary carbides which increase carbide density. The carbide density was measured by using image analysis software and it was $4.3 \%$ for conventional (HT) sample. Whereas it is increased $5.7 \%$ for cryogenically treated sample Cryogenic treatment induces residual compressive stresses which then released during soft tempering creating nucleation sites for fine carbides [12]. 
Smaller carbide size and their more uniform distribution were also observed in case of deep cryogenically treated (DCT only) sample. The above findings are in good agreement with the published literature [13].

Deep cryogenic treatment also transforms retained austenite to martensite. The XRD analysis of conventional (HT) and deep cryogenically treated samples do not show presence of any retained austenite. Though conventional harden and tempered sample expected to have some amount of retained austenite (RA), but this amount is very low (below 4\%) and it is difficult to measure. Almost complete transformation of austenite to martensite during hardening and tempering may be due to oil quenching used during hardening of this tool steel. Though small amount of RA was there after conventional treatment, DCT ensures complete transformation of retained austenite to martensite [1] [2] [3] [4].

\subsection{Mechanical Properties}

The hardness and impact toughness of conventionally (HT) and cryogenically (DCT32) treated samples are presented in Table 3. Cryogenically treated sample resulted in slightly higher hardness as compared to conventional sample which may be due to increased carbide density and complete transformation of retained austenite to martensite. Moreover additional microstructural modifications, like finer martensitic structure, more uniform distribution of carbides and martensitic needles significantly increases impact toughness of cryogenically treated samples.

\subsection{Stress Rupture Performance}

The equations Stress rupture performance of Conventional heat treatment and deep cryogenic treatment (DCT) is given in Figure 6. This shows significant impact of deep cryogenic heat treatment on rupture time. Rupture time for cryogenically treated sample is increased by $11.49 \%$ compared to conventionally heat treated sample. It may note that rise in rupture time could to attributed to increase in small sized tertiary carbides and their more homogeneous distribution.

\subsection{Wear Performance}

The wear performance of tool steels is very complex phenomenon and it not only depends on the hardness but also on the microstructure, process variables and properties of sliding materials [17]. In the present research work, wear performance in terms of wear rate for heat treated and deep cryogenically treated at

Table 3. Mechanical properties of HT and DCT samples.

\begin{tabular}{ccc}
\hline Sample treatment condition & Hardness (HRC) & Impact toughness (J) \\
\hline HT & 50.1 & 16.2 \\
DCT & 52.3 & 19.1 \\
\hline
\end{tabular}


32 hours (DCT 32) material conditions is given in Figure 7. The wear rate of cryogenically treated samples (DCT32) are significantly lower than conventional harden and tempered (HT) samples. It is clearly due to formation of tertiary carbides and their increased density during deep cryogenic treatment. Deep cryogenically treated sample reduces wear rate by $32 \%$ as compared to conventional harden and tempered (HT) sample.

\section{Conclusions}

To summarize, this study explored the effect of deep cryogenic treatment on AISI H-13 tool steel and analyzed mechanisms behind it. The following conclusions can be drawn from the work:

Deep cryogenic treatment (DCT) causes microstructural changes like fine martensitic structure, increase in carbide density and their uniform distribution which improves hardness impact toughness, wear and stress rupture property as compared to conventional harden and tempered (HT) samples.

Stress rupture time increased by $11.49 \%$ as compared to heat treated samples.

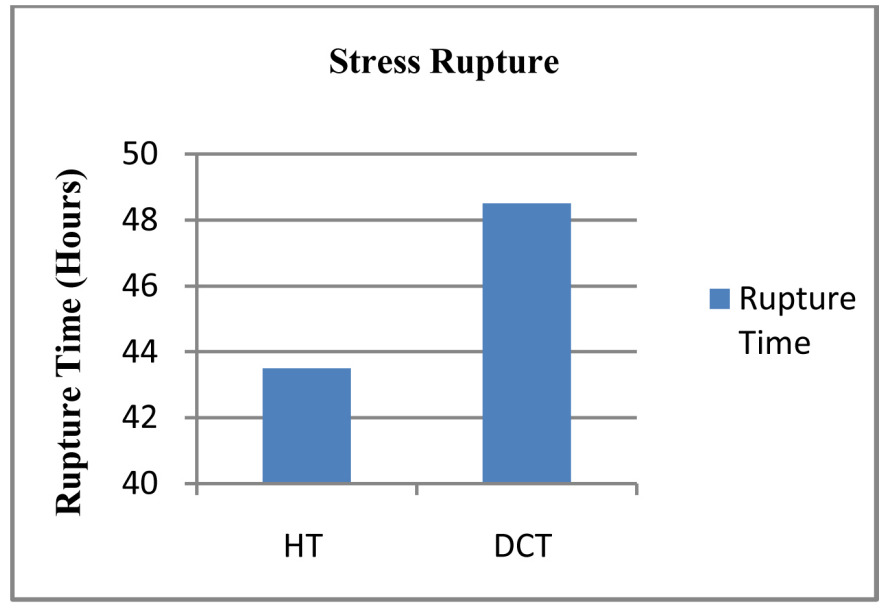

Figure 6. Rupture time (Hrs) for heat treated and cryogenically treated sample.

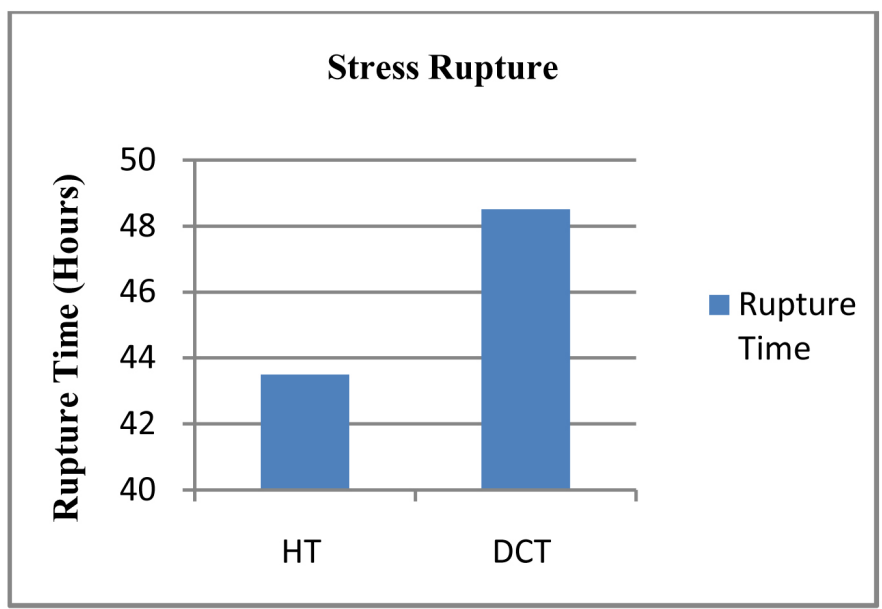

Figure 7. Wear rate for different conditions of sample. 
Impact toughness of cryogenically treated samples is improved by 17.9.

Reduction in wear rate by $32 \%$ is observed as compared to conventional harden and tempered sample.

\section{Acknowledgements}

The authors gratefully acknowledge the extended support provided to this work by KCTI (Kalyani Centre for Technology and Innovation) for providing financial funding, laboratory and library facilities. The authors also acknowledge the support provided by Bharat Forge Ltd., Pune and DSIR (Department of Scientific and Industrial Research), Govt. of India. Finally, the authors would like to express special thanks and gratitude to review committee and top management of Bharat Forge Ltd for granting the permission to publish/present the research work. The authors also wish to place their sincere thanks to department of metallurgy, college of engineering Pune (COEP) for providing experimentation facility.

\section{References}

[1] Naravade, R.H., Gujar, U.N. and Kharde, R.R. (2012) Optimization of Cryogenic Treatment on Wear Behaviour of D6 Tool Steel by Using DOE/RSM. International Journal of Engineering and Advanced Technology (IJEAT), 2.

[2] Rout, S., Behera, A. and Mishra, S.C. Assurance of Quality Improvement for Tool Steel by Cryo-Processing. Advances in Mechanics and Materials.

[3] Behera, A. and Mishra, S.C. (2012) Comparative Study of Cryo-Treated Steel. International Journal of Scientific \& Technology Research, 1.

[4] da Silva, F.J., Franco, S.D., Machado, A.R., Ezugwu, E.O. and Souza Jr., A.M. (2006) Performance of Cryogenically Treated HSS Tools. Wear, 261. https://doi.org/10.1016/j.wear.2006.01.017

[5] Chaphalkar, S.P. and Lele, M.M. Effect of the Soaking Period in Deep Cryogenic Treatment on Tool Life and Wear Resistance of Tool Steel.

[6] Dhokey, N.B., Dandawate, J.V. and Rawat, R. (2013) Effect of Cryosoaking Time on Transition in Wear Mechanism of M2 Tool Steel. Hindawi Publishing Corporation, ISRN Tribology.

[7] Candane1, D., Alagumurthi, N. and Palaniradja, K. (2013) Effect of Cryogenic Treatment on Microstructure and Wear Characteristics of AISI M35 HSS. International Journal of Materials Science and Applications.

[8] Dhokey, N.B., Hake, A., Kadu, S., Bhoskar, I. and Dey, G.K. (2013) Influence of Cryoprocessing on Mechanism of Carbide Development in Cobalt-Bearing HighSpeed Steel (M35). Metallurgical and Materials Transactions A, 44A.

[9] Akhbarizadeh, A., Shafyei, A. and Golozar, M.A. (2009) Effects of Cryogenic Treatment on Wear Behavior of D6 Tool Steel. Materials and Design, 30, 3259-3264. https://doi.org/10.1016/j.matdes.2008.11.016

[10] Dhokey, N.B., Hake, A.R., Thavale, V.T., Gite, R. and Batheja, R. (2014) Microstructure and Mechanical Properties of Cryotreated SAE8620 and D3 Steels. Current Advances in Materials Sciences Research (CAMSR), 1.

[11] Chaudhari, S.B., Shekhawat, S.P. and Kushwaha, A.S. (2012) Advanced Technology of Cryoprocessing for the Enhancement of Tool Material Machining Characteristics: 
A Review. International Journal of Emerging Technology and Advanced Engineering, 2.

[12] Chaphalkar, S.P. and Lele, M.M. Effect of the Soaking Period in Deep Cryogenic Treatment on Tool Life and Wear Resistance of Tool Steel.

[13] Koneshlou, M., Asl, K.M. and Khomamizadeh, F. (2011) Effect of Cryogenic Treatment on Microstructure, Mechanical and Wear Behaviors of AISI H13 Hot Work Tool Steel. Cryogenics, 51.

[14] Latas, Z., Ciski, A. and Suchmann, P. (2006) Cryogenic Treatment and Combination of Nitriding and Cryogenic Treatment of Hot Forging Tools. 4th WSEAS Int. Conf. on Heat Transfer, Thermal Engineering and Environment, Elounda, 21-23 August 2006.

[15] Perez, M., Rodriguez, C. and Belzunce, F.J. (2014) The Use of Cryogenic Thermal Treatments to Increase the Fracture Toughness of a Hot Work Tool Steel Used to Make Forging Dies. 20th European Conference on Fracture (ECF20). https://doi.org/10.1016/j.mspro.2014.06.100

[16] Çiçek, A., Kara, F., Kivak, T. and Ekici, E. (2013) Evaluation of Machinability of Hardened and Cryo-Treated AISI H13 Hot Work Tool Steel with Ceramic Inserts. Int. Journal of Refractory Metals and Hard Materials.

[17] Bhawar, V., Khot, S., Kattire, P., Mehta, M. and Singh, R.K.P. Effect of Deep Cryogenic Treatment (DCT) on AISI H13 Tool Steel. Proceedings of the 28 th ASM Heat Treating Society Conference.

Submit or recommend next manuscript to SCIRP and we will provide best service for you:

Accepting pre-submission inquiries through Email, Facebook, LinkedIn, Twitter, etc. A wide selection of journals (inclusive of 9 subjects, more than 200 journals)

Providing 24-hour high-quality service

User-friendly online submission system

Fair and swift peer-review system

Efficient typesetting and proofreading procedure

Display of the result of downloads and visits, as well as the number of cited articles Maximum dissemination of your research work

Submit your manuscript at: http://papersubmission.scirp.org/

Or contact msce@scirp.org 